\title{
Sylvain Santi, Georges Bataille, à l'extrémité fuyante de la poésie
}

Fabio Scotto

\section{(2) OpenEdition}

1 Journals

\section{Edizione digitale}

URL: http://journals.openedition.org/studifrancesi/8366

DOI: $10.4000 /$ studifrancesi.8366

ISSN: 2421-5856

\section{Editore}

Rosenberg \& Sellier

\section{Edizione cartacea}

Data di pubblicazione: 1 mai 2009

Paginazione: 207-208

ISSN: 0039-2944

\section{Notizia bibliografica digitale}

Fabio Scotto, «Sylvain Santi, Georges Bataille, à l'extrémité fuyante de la poésie», Studi Francesi [Online], 157 (LIII | I) | 2009, online dal 30 novembre 2015, consultato il 11 janvier 2021. URL: http:// journals.openedition.org/studifrancesi/8366 ; DOI: https://doi.org/10.4000/studifrancesi.8366

Questo documento è stato generato automaticamente il 11 janvier 2021.

\section{(c) $(1) \&$}

Studi Francesi è distribuita con Licenza Creative Commons Attribuzione - Non commerciale - Non opere derivate 4.0 Internazionale. 


\title{
Sylvain Santi, Georges Bataille, à l'extrémité fuyante de la poésie
}

\author{
Fabio Scotto
}

\section{NOTIZIA}

SYLVAIN SANTI, Georges Bataille, à l'extrémité fuyante de la poésie, Amsterdam-New York, Rodopi, 2007 («Faux Titre», 303), pp. 364.

1 Sylvain Santi affronta un aspetto dell'opera troppo spesso ritenuto «question mineure» (p. 7) e perciò negletto dalla critica, che ritiene Bataille prevalentemente un filosofosaggista e un romanziere, mentre invece poesia vi è nei suoi scritti un po' ovunque, tanto è vero che essa invade, come già in Nietzsche, anche i suoi saggi.

2 La monografia si compone di otto capitoli. Nel primo, Influence du surréalisme, l'A. mostra come, fin dal tempo di Documents, Bataille avversi per anti-idealismo manifesto una poesia troppo spesso coincidente con l'ideale e «apaisante» (p. 13), cui egli oppone una poesia violenta fondata sull'inestetismo escretorio dell'eccesso e sul fallimento. Il secondo capitolo, Dépasser les notions infiniment, dice quanto la poesia scaturisca da un «bouleversement de la syntaxe» (p. 56) trasgressivo della norma, che insinua il disordine nel discorso, in ciò prossima alla lezione di Sade, d'Artaud e di Klossowski, i quali sopprimono ogni distanza tra essa e la vita. Il terzo capitolo, Poésie et expérience, studia il periodo 1933-1939, nel quale la parola "poésie» scompare dagli scritti di Bataille, pur venendo essa adottata come forma, secondo lo stilema meditativo buddista della ripetizione e rivelando «un corps placé sous le régime d'une sexualité violente [...] que l'esprit et le discours ne peuvent dominer ou maîtriser» (pp. 72-73). Interessante qui il rimando a Deleuze e Guattari, per la visagéification del corpo, e il confronto tematico con il Sartre de La Nausée, che anche caratterizza l'incipit del quarto capitolo, La Haine et l'image, incentrato, in un fitto confronto con Baudelaire, Rimbaud e Nietzsche, sull'intollerabilità del poetico per la vera poesia, la quale si sprigiona nell'istante della sua mancanza e del rifiuto d'essere che fin da L'Expérience intérieure fa 
della «haine» la sua sovranità stessa, in un rapporto conflittuale con la rappresentatività delle immagini che la profanazione ironica sfida dall'infera luce dell'immondo di una poesia letterale a-immaginifica (p. 140). Negli ultimi capitoli (L'CEuvre sacrifiée, La Poésie et la nuit, Se mettre en jeu, Vers une communauté poétique) Santi si sforza di approdare per avvicinamenti progressivi a una nozione di poesia batailliana desumibile dai suoi stessi assunti e modi operativi, dalla sua sacralità sacrificale immorale che, come sottolinea Jean-Luc Nancy, si espone (p. 149) alla teorizzazione della riuscita come «absence d'œuvre» (p. 165), in ciò distante dall'automatismo surrealista e dal soggettivismo hegeliano e più prossima a Blanchot, un pensiero dell'impossibile e dell'eterogeneo che culmina in una notte intesa come luminoso nulla (p. 216) da cui affiora l'«ipse» (p. 269) nell'eloquenza del silenzio, in una «dépense» che è «communication» (p. 339). Ampia e ben documentata la Bibliographie (pp. 341-362). 